\title{
UN VASO DE ALABASTRO PROCEDENTE DE ADRA CONSERVADO EN EL MUSEO DE ALMERÍA
}

\author{
POR \\ EDUARDO GARCÍA ALFONSO \\ Universidad de Málaga
}

\begin{abstract}
RESUMEN
Se estudia un vaso de alabastro inédito procedente de la localidad almeriense de Adra, pieza que se añade a la ya numerosa serie de recipientes de origen egipcio conocida en las costas meridionales de la Península durante los siglos VIII-VII a.C. El principal interés de este hallazgo casual radica en su carácter funerario, siendo indicio de una posible necrópolis de época fenicia arcaica en las inmediaciones del asentamiento colonial de Abdera.
\end{abstract}

\section{SUMMARY}

A previously unpublished alabaster jar from Adra, a coastal site some $50 \mathrm{~km}$ to the west of Almería is yet another example of a numerous class of Egyptian containers of the 8th-7th centuries BC discovered on the southern coast of the Iberian Peninsula. A casual find, the funerary character of this piece suggests that there may have been a cemetery of the Early Phoenician Period in the immediate neighbourhood of the colonial settlement of Abdera.

De los asentamientos fenicios de época arcaica situados en la costa andaluza, Abdera ${ }^{\prime}$ resulta uno de los peor conocidos a causa de la poca atención que, hasta hace poco, le han dedicado los investigadores ${ }^{2}$. Desde Antonio de Nebrija, esta ciudad antigua fue localizada en la localidad almeriense de Adra debido al parecido del topónimo y a las vagas noticias de los textos clásicos. En el siglo xIX, la aparición en el vecino Cerro de Montecristo de esculturas, monedas e inscripciones latinas llevaron a situar el Municipium Abderitanum en este lugar. Los orígenes fenicios de la ciudad, mencionados expresamente por Estrabón (III, 4, 3), fueron señalados por numerosos humanistas de nuestro Siglo de Oro

${ }^{1}$ El topónimo 'bdrt lo encontramos en caracteres púnicos en las monedas emitidas por la ciudad desde el siglo II a.C. hasta la época de Tiberio, siendo transcrito por las fuentes clásicas como Abdera. J. Sanmartín $(1994,231)$ ha puesto en duda que este topónimo sea de origen fenicio, señalando su pertenencia a un adstrato egeo, norteafricano o paleomediterráneo.

2 Un trabajo global es el reciente libro de M. J. López Medina (1996), aunque centrado fundamentalmente en la época romana. y en ellos insistió A. Schulten (1945, 69; 1955, 124). Mientras, otros investigadores modernos se inclinaron por considerar Abdera como una fundación originalmente griega, que, después de la batalla de Alalia, pasó a manos de los cartagineses (García y Bellido, 1952 a, 423; 1952 b, 530). Para las primeras excavaciones científicas en el Cerro de Montecristo habrá que esperar a los años 1970 y 1971, pero los resultados de estos trabajos no dilucidaron gran cosa sobre los primeros tiempos del asentamiento, ya que sólo se alcanzaron niveles de mediados del siglo IV a.C., siendo el grueso del material de época romana (Fernández-Miranda y Caballero Zoreda, 1975). La constatación de niveles más antiguos en el lugar vino poco después, al localizarse en la ladera oriental del cerro, desmontada por tareas de abancalamiento, fragmentos de platos y cerámicas polícromas del siglo vII (Schubart, 1982, 86-87). Finalmente, en 1986 una intervención de urgencia en el lugar no sólo ha confirmado la existencia de poblamiento fenicio de época arcaica en el Cerro de Montecristo, sino que ha llevado su inicio a mediados del siglo viII a.C. (Carrilero et alii, 1988; Suarez et alii, 1989; López Castro et alii, 1991).

El Cerro de Montecristo responde perfectamente al patrón de asentamiento establecido para los núcleos fenicios del periodo arcaico en la costa mediterránea andaluza (Aubet, 1994, 265-268). Se encuentra situado en el extrarradio de Adra, asediado por la expansión del casco urbano. Es un altozano de forma aproximadamente triangular que alcanza casi los $50 \mathrm{~m}$ sobre el nivel del mar, hoy totalmente transformado por tareas agrícolas y edificación de algunos inmuebles. El río Adra o río Grande bordeaba la ladera oriental del cerro, zona por donde discurría la antigua línea de costa. Aquí, la desembocadura del río formaba un pequeño estuario, excelente como fondeadero natural (Hoffmann, 1988, 49-53). El valle fluvial que quedaba al norte del Cerro de Montecristo constituía una magnífica vía de penetración hacia el interior, poniendo en contacto la costa con la sierra de Gádor y la zona 


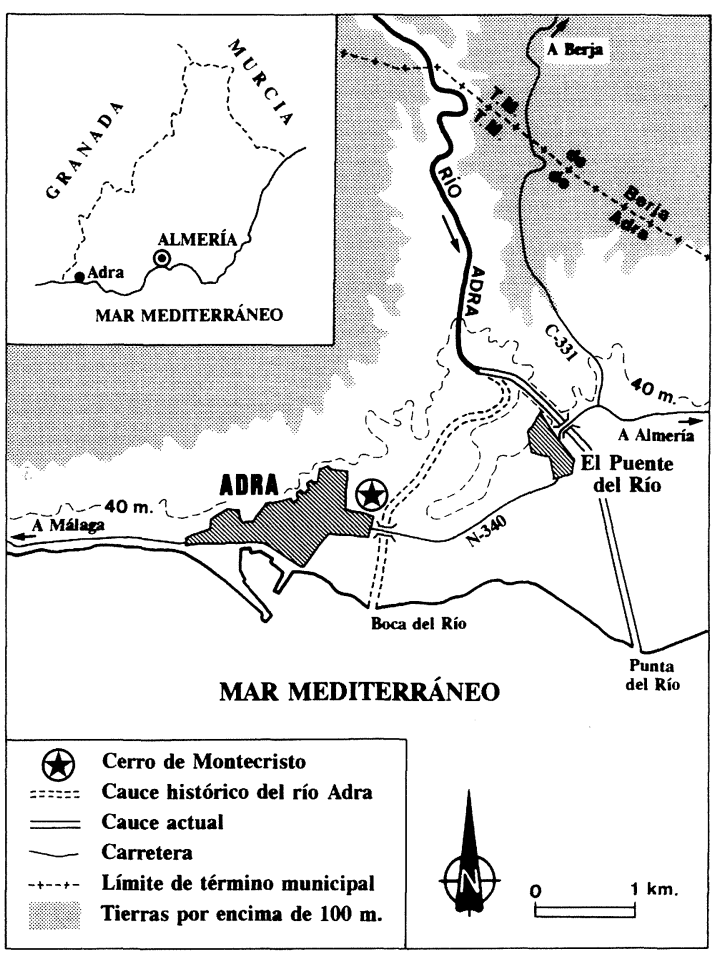

Fig. 1.-Cerro de Montecristo y su entorno.

oriental de La Alpujarra. Actualmente, el paisaje está totalmente transformado, debido al progresivo avance del litoral y al desvío en 1872 del río Adra a $2 \mathrm{~km}$ al este, habiéndose convertido el antiguo lecho en tierras de cultivo (fig. 1).

Tradicionalmente, el Cerro de Montecristo ha venido siendo lugar de aparición de hallazgos casuales. Bien conocidos resultan diversos fragmentos de cerámica griega del siglo v a.C. (Trías de Arribas, 1967, 448), la serie epigráfica del Municipium Abderitanum y una cabeza femenina de época posiblemente adrianea (Fernández-Miranda y Caballero Zoreda, 1975, 177-193 y 196-199). Entre estos disiecta membra, queremos dar a conocer una pieza que ha permanecido inédita hasta hoy, pese a que resulta de gran interés para la fase fenicia arcaica de Abdera: un vaso de alabastro completo, conservado actualmente en la sección arqueológica del Museo de Almería (García Alfonso, Martínez Enamorado y Morgado Rodríguez, e.p.).

Según la información que consta en el Museo de Almería ${ }^{3}$, este vaso fue hallado casualmente en el

${ }^{3}$ Núm. de inventario 75.038. El vaso fue donado por la familia Utrera Solé, ingresando en el Museo en 1983. Desde aquí quiero agradecer a D. Miguel Angel Fernández, conservador del Museo de Almería, su amabilidad y las facilidades dadas para el estudio de esta pieza.
Cerro de Montecristo, pero no conocemos detalles concretos de la forma en que esto sucedió ni la fecha aproximada del descubrimiento. La aparición de la pieza íntegra y el carácter predominantemente funerario de este tipo de hallazgos hace plausible pensar, con las necesarias reservas, que no proceda exactamente del citado enclave, sino de algún lugar muy próximo donde se ubicase la necrópolis arcaica de Abdera, como luego comentaremos. Dada la tradición existente en Adra sobre hallazgos arqueológicos en el Cerro de Montecristo, no es descabellado pensar que se le atribuyera dicho origen, aunque hubiera sido hallado en algún paraje vecino.

El vaso del Museo de Almería es de calcita (carbonato cálcico) de color blanco-amarillento, con destacadas vetas. Este material es el denominado «alabastro egipcio» u «oriental», diferente del verdadero alabastro yesoso (sulfato cálcico). La pieza mide $32 \mathrm{~cm}$ de altura, con un diámetro de boca de $13 \mathrm{~cm}$, alcanzando su anchura máxima en el tercio superior del cuerpo con 16'5 cm. Por su tamaño, este vaso de Adra se encuentra entre los de medianas dimensiones conocidos en la Península Ibérica. Su estado de conservación es bueno, salvo una pequeña pérdida en parte de la boca. El vaso presenta borde apuntado vertical, no destacado del cuerpo, con boca tendente al estrechamiento. Inmediatamente debajo de ésta se encuentran dos pequeñas asas simples enfrentadas, de 3' $3 \mathrm{~cm}$ de altura. Ambas son de forma semicircular, aunque una presenta toques de bisel, lo que motiva que no sean exactamente iguales. El agujero de aprehensión es bastante pequeño, de $4 \mathrm{~mm}$ de sección, y en los dos casos perfora tangencialmente parte de las paredes del vaso. El cuerpo adopta un perfil ovoide muy alargado: se ensancha desde la boca, para alcanzar su mayor diámetro por debajo de las asas, estrechándose progresivamente hasta el pie, que es parabólico. En cuanto al tratamiento superficial, muestra cuidado pulimento tanto al exterior como al interior, Finalmente, la pieza no presenta ningún tipo de inscripción o marca epigráfica (figs. 2 y 3 ).

Por su tipología, el vaso de Adra podría encuadrarse dentro del grupo de jarras hebenet, caracterizadas porque la parte inferior se estrecha en relación con la superior. Son piezas bien conocidas en Egipto, donde se fabricaban en alabastro desde la dinastía XVIII, aunque en cerámica aparecen en momentos anteriores. En el País del Nilo se utilizaban para guardar productos de cierta categoría, tales como vino, cerve$\mathrm{za}$, aceite, miel, fruta o incienso. Igualmente, esta forma es muy abundante en cerámica en la región sirio-palestina, de ahí que se la conozca también con el nombre de jarra o ánfora cananea (Padró i Parceri- 


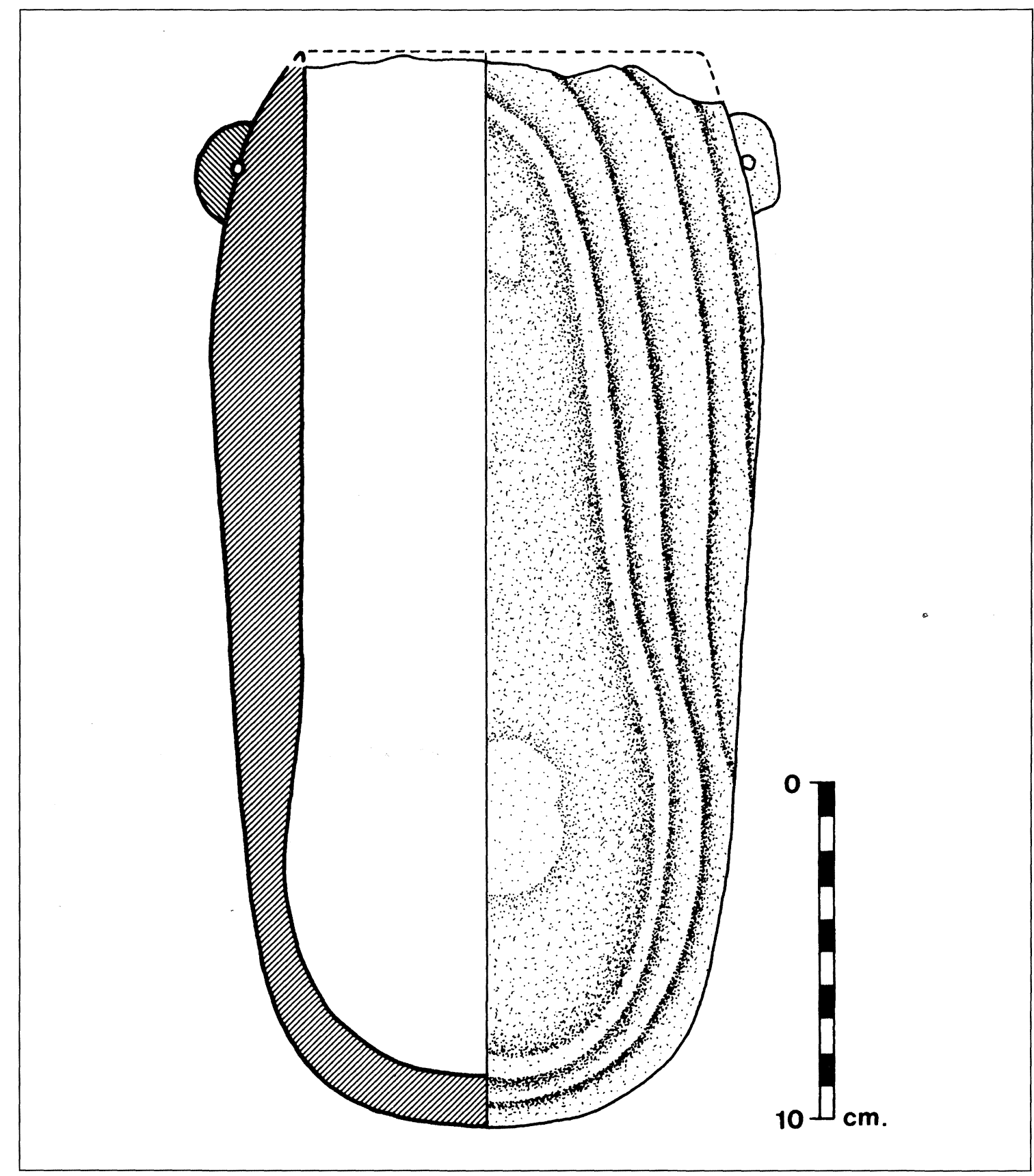

Fig. 2.-Vaso de alabastro de Adra. Museo de Almería. Escala 1/2.

sa, 1983, 50). Vasos de alabastro tipo hebenet no faltan en el mediodía de la Península Ibérica, siendo los más cercanos a la pieza de Adra los aparecidos en la tumbas 11 y 17 del Cerro de San Cristóbal de Almuñécar (Pellicer Catalán, fig. 13, 1 y fig. 26, 1), aunque son diferentes al que nos ocupa por la forma de su parte superior, ya que poseen cuellos con gollete estrecho y boca ligeramente exvasada.
La forma de la boca, sin cuello ni labio y con las paredes inclinadas al interior las conocemos también en diferentes vasos de alabastro aparecidos en el litoral andaluz, aunque resultan de tamaño más pequeño que el de Adra. Muy similar es el documentado en la tumba 9 de la necrópolis onubense de La Joya, hallado en un contexto del siglo viI (Garrido Roiz, 1970, fig. 35, 1). También cabe citar una 


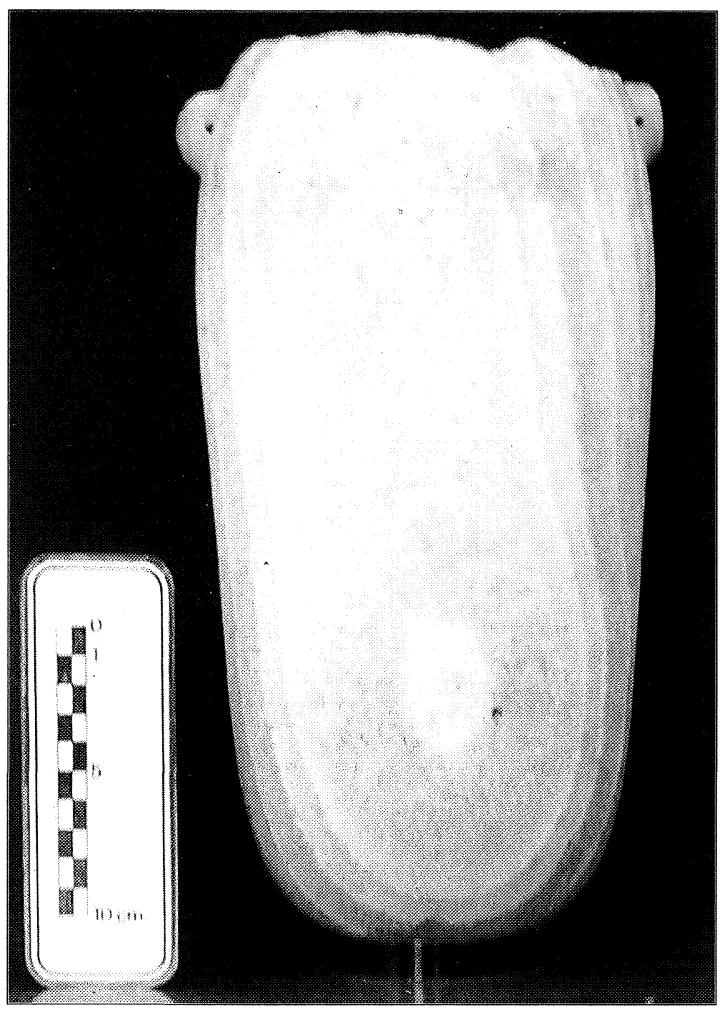

Fig. 3.-Vaso de alabastro. Adra. Museo de Almería.

de las piezas halladas en 1792 en los alrededores de Torre del Mar (Málaga), hoy conservada en el Museo Arqueológico Nacional y fechada en los siglos vIII-VII a.C. (Pérez Die, 1976, 907, núm. 4, fig. 4).

En Egipto también existen vasos similares dentro de contextos del siglo viI, como los aparecidos en Riqueh y Tell el-Yahudiya (cfr. Pérez Die, 1976, nota 20 bis). Otros ejemplares se han documentado en las excavaciones españolas de Heracleópolis Magna. En este lugar del Egipto Medio se han localizado cuatro fragmentos de vasos con una boca muy parecida al hallazgo de Adra, aunque se trata de recipientes más pequeños y estrechos, cuyas paredes interiores tienen una tendencia convergente que no aparece en el vaso almeriense (Molinero Polo, 1995, lám. 80, g, m, ñ, o). Las piezas heracleopolitanas se sitúan a finales del siglo viII a.C. o primera mitad del viI.

Parece adecuado atribuir al vaso de Adra una cronología de los siglos viII-VII a.C. Las excavaciones de 1986 en el Cerro de Montecristo han adelantado el comienzo del poblamiento fenicio en el lugar hasta mediados del siglo viII, por lo que la presencia de este vaso de alabastro no está en contradicción con la secuencia arqueológica del yaci- miento. La aparición de la pieza completa nos hace reflexionar sobre su posible procedencia de un enterramiento del periodo fenicio arcaico, bien constituido por una tumba aislada o formando parte de una necrópolis. Debido a la escasez de datos sobre la organización espacial de la Abdera arcaica, aún es pronto para pronunciarse en un sentido u otro. La posibilidad de existencia de sepulturas dispersas en torno al asentamiento principal ha sido puesta de manifiesto a raíz de los hallazgos de Lagos, en la provincia de Málaga (Aubet et alii, 1991, 18-19).

Como se está viendo en los últimos años, la presencia de vasos de alabastro de fabricación egipcia utilizados como urnas cinerarias en las necrópolis fenicias de la costa andaluza no resulta un hecho excepcional, como pudo pensarse poco después del descubrimiento de las tumbas del Cerro de San Cristóbal de Almuñécar (Pellicer Catalán, 1962, 66). Las piezas recuperadas con posterioridad en Trayamar (Schubart y Niemeyer, 1976, 228-231) y recientemente en Lagos (Aubet et alii, 1991, 19-24), además de la puesta en valor de algunos de estos objetos conservados en diferentes lugares, confirman que los vasos de alabastro fueron objetos relativamente corrientes en ciertos enterramientos. En cambio, sí resulta sorprendente la abundancia con que estos bienes de lujo aparecen en el sur de la Península Ibérica en contraste con su escasez en otros ámbitos fenicios. En Cartago sólo se conocen dos ejemplares, uno en Tanit I y otro en la necrópolis de la colina de Juno (Cintas, 1970, 436, lám. 18, núms. 80-81), por lo que dichos vasos no pasan de tener un carácter testimonial en la gran metrópoli norteafricana. En el resto del Mediterráneo la presencia de este tipo de recipientes se reduce a una o dos piezas documentadas en escasos puntos de Etruria, Grecia y Chipre. Igual sucede en el Próximo Oriente, con unos pocos vasos conocidos en ambientes palaciegos de Samaría, Assur y Nimrud ${ }^{4}$. Lógicamente, la excepción es Egipto, centro de fabricación de estos productos, donde son conocidos en la tipología egiptológica como «botellas». Una particularidad a señalar con respecto a las piezas que se conocen en el litoral andaluz es el pequeño tamaño de la gran mayoría de los vasos documentados en Egipto. La excepción en cuanto a sus grandes dimensiones son los hallados en las necrópolis reales faraónicas de Tanis y el-Kurru, circunstancia que también encontramos en los contextos cortesanos de Israel y Asiria. Esta cuestión obliga a plantearse por qué piezas

${ }^{4}$ Toda la bibliografía sobre hallazgos de vasos de alabastro egipcios fuera de la Península Ibérica es recogida por M.C. Pérez Die (1976, 909, nota 29). 
de carácter áulico llegaron hasta el Extremo Occidente y escasean en lugares más cercanos a los centros de producción, caso de la Cartago arcaica. En la resolución de esta cuestión no cabe duda de que juega un importante papel la estructura de la sociedad colonial fenicia arraigada en las costas andaluzas y sus mecanismos de relación con el Mediterráneo oriental.

Sobre esta hipotética necrópolis abderitana nada sabemos. Su misma ubicación es una incógnita. Si bien las noticias sobre el lugar de aparición del vaso señalan al Cerro de Montecristo, es costumbre que los enterramientos fenicios de época arcaica se ubiquen fuera del núcleo habitado y separados de éste por un curso de agua o un pequeño brazo de mar, seguramente por imperativos rituales cuyos detalles se nos escapan. Igualmente, suele haber un cierto dominio visual de la necrópolis desde el poblado. Esta situación es la que vemos reflejada en asentamientos como Toscanos, Morro de Mezquitilla y Almuñécar. Incluso, cuando la colonia fenicia se ubica en una isla, la necrópolis se sitúa en algún islote vecino o en tierra firme, casos de Cádiz o la misma Tiro (Aubet, 1994, 267). Por ello, aunque sólo sea a nivel de hipótesis, está dentro de lo posible que el vaso proceda de alguno de los pequeños altozanos que bordean la margen izquierda del antiguo cauce del río Adra, actualmente muy alterados por diversas actividades humanas. Son elevaciones alomadas que rondan los 40-60 m de altitud, cuya localización en la ribera opuesta al Cerro de Montecristo las convierte en el emplazamiento ideal para la necrópolis arcaica de Abdera.

\section{BIBLIOGRAFÍA}

Aubet, M.E., 1994, Tiro y las colonias fenicias de Occidente. Edición ampliada y puesta al día, Barcelona.

Aubet, M.E. et alii, 1991, Sepulturas fenicias en Lagos (Vélez-Málaga, Málaga), Sevilla.

Carrilero, M. et alii, 1988, Abdera fenicia. Excavaciones en el Cerro de Montecristo (Adra, Almería), Homenaje al Padre Tapia (Almería, 1986), 137-147.

CinTAS, P., 1970, Manuel d'archéologie punique, vol. I: Histoire et archéologie comparées. Chronologie des temps archaïques de Carthage et des villes phéniciennes de l'Ouest, París.

Fernández-Miranda, M. y Caballero Zoreda, L., 1975, Abdera. Excavaciones en el cerro de Montecristo (Adra, Almería), EAE, 85, Madrid.
García Alfonso, E; Martínez Enamorado, V. y Morgado Rodríguez, A., e.p., Museos Arqueológicos de Andalucía, vol. II: Almería, Granada, Jaén y Málaga.

García y Bellido, A., 1952 a, Las colonias púnicas, Historia de España (dir. por R. Menéndez Pidal), vol. I,2: España Protohistórica, Madrid, 389-462.

—, 1952 b, La colonización fócea desde los comienzos hasta su fin en la batalla naval de Alalíe (siglo VII, hacia el 535), Historia de España (dir. por R. Menéndez Pidal), vol. I,2: España Protohistórica, Madrid, 511-558.

GARRIDO RoIz, J.P., 1970, Excavaciones en la necrópolis de «La Joya», Huelva $\left(1^{a}\right.$ y $2^{a}$ Campañas $)$, EAE, núm. 71, Madrid.

HoffMANN, G., 1988, Holozänstratigraphie und Küstenlinienverlagerung an der andalusischen Mittelmeerküste, Berichte Fachbereich Geowissenschaften Universität Bremen, 2, Bremen.

López Castro, J.L. et alii, 1991, La colonización fenicia en Abdera: nuevas aportaciones, Atti del II Congresso Internazionale di Studi Fenici e Punici (Roma, 1987), vol. III, 981-989.

López Medina, M.J., 1996, El municipio romano de Abdera. Una aproximación histórica, Almería.

Molinero Polo, M.A., 1995, Recipientes de piedra, Excavaciones en Ehnasya el Medina (Heracleópolis Magna), vol. II, Madrid, 203-277.

Padró i PARcerisa, J., 1983, Materiales egipcios del Cerro de San Cristóbal, Almuñécar (Granada). Hallazgos de la campaña de 1963, Almuñécar, Arqueología e Historia, 2, 11-78.

Pellicer Catalán, M., 1962, Excavaciones en la necrópolis púnica «Laurita» del Cerro de San Cristóbal (Almuñécar, Granada), EAE, núm. 17, Madrid.

Pérez Die, M.C., 1976, Notas sobre cuatro vasos egipcios de alabastro procedentes de Torre del Mar (Málaga) conservados en el Museo Arqueológico Nacional de Madrid, Revista de Archivos, Bibliotecas y Museos, 79, 4, 903-918.

Schubart, H., 1982, Asentamientos fenicios en la costa meridional de la Península Ibérica, Primeras Jornadas Arqueológicas sobre colonizaciones orientales (Huelva, 1980), Huelva Arqueológica, 6, 71-99.

Schubart, H. y Niemeyer, H.G., 1976, Trayamar. Los hipogeos fenicios y el asentamiento en la desembocadura del río Algarrobo, EAE, núm. 90, Madrid.

Schulten, A., 1945, Tartessos, Madrid.

_, 1955, Avieno. Ora Maritima (Periplo Massaliota del siglo VI a. de J.C.), junto con los demás testi- 
monios anteriores al año 500 a. de J.C., Fontes Hispaniae Antiquae, fasc. I, $2^{\mathrm{a}}$ ed., Barcelona.

SANMARTín, J., 1994, Toponimia y antroponimia: fuentes para el estudio de la cultura púnica en España, El mundo púnico. Historia, sociedad y cultura (Cartagena, 1990), Murcia, 227-247.
SuÁrez, A. et alii, 1989, Abdera: una colonia fenicia en el sureste de la Península Ibérica, Madrider Mitteilungen, 30, 135-150.

TRÍAS DE ARribas, G., 1967, Cerámicas griegas de la Península Ibérica, vol. I, Valencia. 